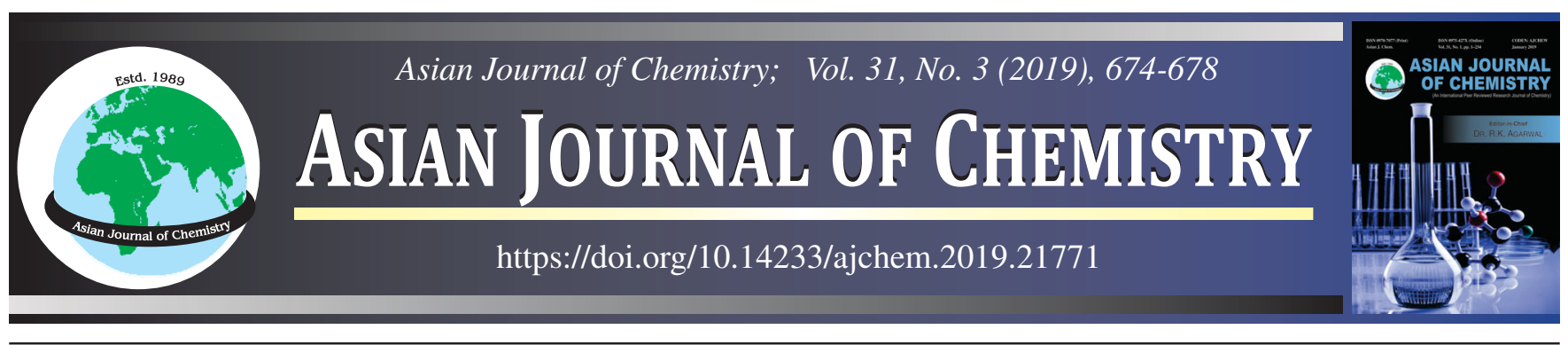

\title{
Physico-Chemical Analysis on Some Polymers in Aqueous Surfactant Solution at Different Temperatures: Acoustical, UV and FTIR Studies
}

\section{N. Chithralekha ${ }^{1, *}$ and A. Panneerselvam ${ }^{2}$}

${ }^{1}$ R\&D Centre, Bharathiar University, Coimbatore-641046, India

${ }^{2}$ Department of Physics, Paavai Engineering College, Pachal-637018, India

*Corresponding author: E-mail: nagarajanchithra@gmail.com

Received: 20 October 2018;

Accepted: 2 December 2018;

Published online: 31 January 2019;

AJC-19267

| The ultrasonic velocity, density and viscosity in mixtures of sorbitan sesquioleate and poly(vinyl pyrrolidone) (PVP), poly(vinyl alcohol) (PVA) and poly(ethylene glycol) (PEG) in different concentration ranges are measured at different temperatures (303, 313 and $323 \mathrm{~K})$ From the experimental data, other related acoustical parameters such as adiabatic compressibility $(\beta)$, intermolecular free length $\left(\mathrm{L}_{\mathrm{f}}\right)$, internal pressure $\left(\pi_{i}\right)$, Rao's constant $\left(R_{a}\right)$, relaxation time $(\tau)$, acoustical impedance $\left(Z_{a}\right)$, absorption coefficient $\left(\alpha / f^{2}\right)$, free volume $\left(V_{f}\right)$, cohesive energy $\left(\mathrm{C}_{\mathrm{E}}\right)$ and solvation number $\left(\mathrm{S}_{\mathrm{n}}\right)$ have been evaluated. In aqueous solutions, surfactant molecule starts to aggregate and form micelle in concentration called as critical micelle concentration (CMC). It is one of the most important physical parameters of the surfactants. These results were interpreted in terms of surfactant-polymer complex reactions. The combinations of surfactant with polymers improve the desired properties of the product and the formation of complex was confirmed by UV and FTIR studies.

Keywords: Sorbitan sesquioleate, Polymers, Molecular interaction, Ultrasonic study.

\section{INTRODUCTION}

The field of ultrasonics has grown enormously in scientific studies and has become a subject of active interest during the recent years. Ultrasonic technique has been found to be more accurate and comprehensive in understanding molecular interactions than the other methods [1]. Nonionic surfactant sorbitan sesquioleate is an emulsifier in cosmetic creams, pharmaceutical creams and ointments. An emulsifier is a thickening agent added to creams and ointments to thicken them and keep them stable [2]. Acoustical studies in polymers have been the subject of research in the previous years and carried out pioneering work on polymer solution using ultrasonic technique [3]. Polymers are used as binders for the formulation of pharmaceutical tablets, for moistening various personal care products, as food additives and adhesives [4].

The interactions between surfactant molecules and polymers in aqueous solutions are of importance to many applications. It is mainly predicted that the critical micelle concentration (CMC) is the most important factor in studies dealing with micellization of surfactants. In general, adsorption charac- teristics at solid-liquid interfaces, the solubilization capacities in water for thinly soluble molecules and liquid-liquid interfacial tensions are altered by the related existence of surfactant and polymer molecules [5-8]. When the temperature value is increased, the value of critical micelle concentration is raised [9].

Various data on molecular interactions from ultrasonic velocity and its derived parameters shows the acoustical properties of surfactant with polymer solutions. Water soluble polymers with increased hydrophobicity, which might progress the soil eliminating capability of the polymer by interrelating with nonionic surfactants by various mechanisms [10]. In the present study an attempt has been made to investigate the behaviour of sorbitan sesquioleate with aqueous solutions of PVP, PVA and PEG at different concentration and different temperatures 303, 313 and $323 \mathrm{~K}$. The effect of sorbitan sesquioleate with PVP, PVA and PEG solution gives more information about complex reactions.

\section{EXPERIMENTAL}

Sorbitan sesquioleate with PVP, PVA and PEG were obtained from Bio-corporals, Chennai. The experimental solutions were

This is an open access journal, and articles are distributed under the terms of the Creative Commons Attribution-NonCommercial-ShareAlike 4.0 (CC BY-NC-SA 4.0) International License which allows readers to freely read, download, copy, distribute, print, search, or link to the full texts of its articles and to use them for any other lawful non-commercial purpose as long as the original source is duly acknowledged. 
prepared by adding a known weight of polymers (PVP, PVA and PEG) with different concentration of sorbitan sesquioleate to a fixed volume of water and attained a clear solution by stirring solution. Stock solution was prepared by using double distilled water. Since polymer solutions are very viscous, low concentrated solution is chosen for the study.

The ultrasonic velocity measurements in the sorbitan sesquioleate with PVP, PVA and PEG solutions were made in the ultrasonic interferrometer (model F81, Mittal Enterprises, New Delhi, India) at a fixed single frequency of $2 \mathrm{MHz}$ and at different temperatures (303, 313 and $323 \mathrm{~K}$ ). The temperature was maintained constant by circulating water from a thermostatically controlled $( \pm 0.1 \mathrm{~K})$ water bath. The values of densities at different temperatures were measured using specific gravity bottle by standard procedure and the viscosity was measured using Ostwald's viscometer with an accuracy of $\pm 0.2 \%$ calibrated with double distilled water.

Thermodynamic parameters: By the use of empirical Jacobson's relations, various thermodynamic parameters [adiabatic compressibility $(\beta)$, intermolecular free length $\left(\mathrm{L}_{\mathrm{f}}\right)$, internal pressure $\left(\pi_{\mathrm{i}}\right)$, acoustic impedance $\left(\mathrm{Z}_{\mathrm{a}}\right)$, cohesive energy $\left(\mathrm{C}_{\mathrm{E}}\right)$, Rao's constant $(\mathrm{R})$ and solvation number $\left.\left(\mathrm{S}_{\mathrm{n}}\right)\right]$ were calculated [11].

$$
\text { Adiabatic compressibility }(\beta)=1 / \mathrm{U}^{2} \rho
$$

where $\rho$ is the density and $U$ is the ultrasonic velocity of the medium using the Newton-Laplace equation.

$$
\text { Intermolecular free length }\left(\mathrm{L}_{\mathrm{f}}\right)=\mathrm{K}_{\mathrm{T}} \beta^{1 / 2}
$$

where $\mathrm{K}_{\mathrm{T}}$ is the temperature dependent constant known as Jacobson's constant $\left(\mathrm{K}_{\mathrm{T}}=2.131 \times 10^{-6}\right), \beta$ is the adiabatic compressibility

$$
\text { Internal pressure }\left(\pi_{\mathrm{i}}\right)=\mathrm{bRT}[\mathrm{K} \eta / \mathrm{u}]^{1 / 2} \rho^{2 / 3} / \mathrm{M}^{7 / 6}
$$

(where, $\mathrm{b}$ stands for cubic packing) $\mathrm{T}$-absolute temperature in Kelvin, where $M_{\text {eff }}$ is the effective molecular weight of the mixture $\left(M_{\text {eff }}=\Sigma m_{i} x_{i}\right.$, where $m_{i}$ and $x_{i}$ are the molecular weight and mole fraction of individual constituents, respectively $\mathrm{K}$ is a temperature independent constant which is equal to $4.281 \times$ $10^{9}$ for all liquids, $\mathrm{R}$ is the universal gas constant, $\eta$-viscosity of the solution) [12].

$$
\begin{gathered}
\text { Rao's constant }\left(\mathrm{R}_{\mathrm{a}}\right)=(\mathrm{M} / \rho)(\mathrm{u})^{1 / 3} \\
\text { Relaxation time }(\tau)=4 / 3 \beta \eta \\
\text { Acoustic impedance }\left(\mathrm{Z}_{\mathrm{a}}\right)=\rho \\
\text { Absorption coefficient }\left(\alpha / \mathrm{f}^{2}\right)=\left(8 \pi^{2} \eta / 3 \rho \mathrm{u}^{2}\right) \\
\text { Free volume }\left(\mathrm{V}_{\mathrm{f}}\right)=\left(\mathrm{M}_{\mathrm{eff}} \mathrm{u} / \mathrm{K} \eta\right)^{3 / 2} \\
\text { Cohesive energy }\left(\mathrm{C}_{\mathrm{E}}\right)=\mathrm{V}_{\mathrm{f}} \pi_{\mathrm{i}}
\end{gathered}
$$

$$
\text { Solvation number }\left(S_{n}\right)=\frac{M_{2}}{M_{1}}\left[1-\left(\frac{\beta}{\beta_{o}}\right)\right]\left[\frac{100-x}{x}\right]
$$

where $M_{1}$ is the molecular weight of the solvent and $M_{2}$ is the molecular weight of the solute, $\beta$ is the adiabatic compressibility of solution and $\beta_{o}$ is the adiabatic compressibility of solvent.

\section{RESULTS AND DISCUSSION}

The aqueous property of ultrasonic velocity, density and viscosity of measured parameters and acoustical parameters sorbitan sesquioleate + PVP, sorbitan sesquioleate + PVA and sorbitan sesquioleate + PEG at temperature 303, 313 and 323 $\mathrm{K}$ are measured (Table-1). The acoustical parameters such as adiabatic compressibility $(\beta)$, intermolecular free length $\left(L_{f}\right)$, internal pressure $\left(\pi_{\mathrm{i}}\right)$, Rao's constant $\left(\mathrm{R}_{\mathrm{a}}\right)$, relaxation time $(\tau)$, acoustical impedance $\left(Z_{a}\right)$, absorption coefficient $\left(\alpha / f^{2}\right)$, free volume $\left(\mathrm{V}_{\mathrm{f}}\right)$, cohesive energy $\left(\mathrm{C}_{\mathrm{E}}\right)$ and solvation number $\left(\mathrm{S}_{\mathrm{n}}\right)$ have been computed.

Ultrasonic velocity of the binary mixture of non-ionic surfactant sorbitan sesquioleate with polymers increase with an increasing value of concentration of sorbitan sesquioleate. Initially the velocity increased and attains a maximum value at a particular concentration (critical micelle concentration $(\mathrm{CMC})$ ) and then the velocity value decreased. At CMC collection of monomers to form groups known as micelles take place hence at $\mathrm{CMC}$ ultrasonic velocity is maximum [13]. The increase in velocity is due to the intermolecular hydrogen bonding between the molecules. The variation of ultrasonic velocity with different concentration and temperature as shown in Fig. 1.

In the case of sorbitan sesquioleate with PVA mixture the $\mathrm{CMC}$ value occurs at 3:1 ratio. In other two mixtures of sorbitan sesquioleate + PVP and sorbitan sesquioleate + PEG the CMC value occurs at 4:1 ratio. Because in the PVA mixture, the concentration is very high due to its high molecular weight that is $89000 \mathrm{~g} / \mathrm{mol}$. So for PVA mixture CMC occurs quickly. Owing to the ultrasonic velocity mechanism should yield the increase in density with increase in concentration.

The viscosity of the binary mixture increases with increase in concentration. When a solute is added to a solvent, then the solvent becomes more viscous, particularly in the case of solid solute. So that, the mixture became thick liquid, less fluidity and hence with high viscosity. The increase in viscosity with concentration is showed inter chain forces over solvent-solvent forces and increases the relaxation time with concentration.

Adiabatic compressibility decreases with increase of concentration of non-ionic surfactant sorbitan sesquioleate, which shows in Fig. 2. This can be explained in terms of the electro-
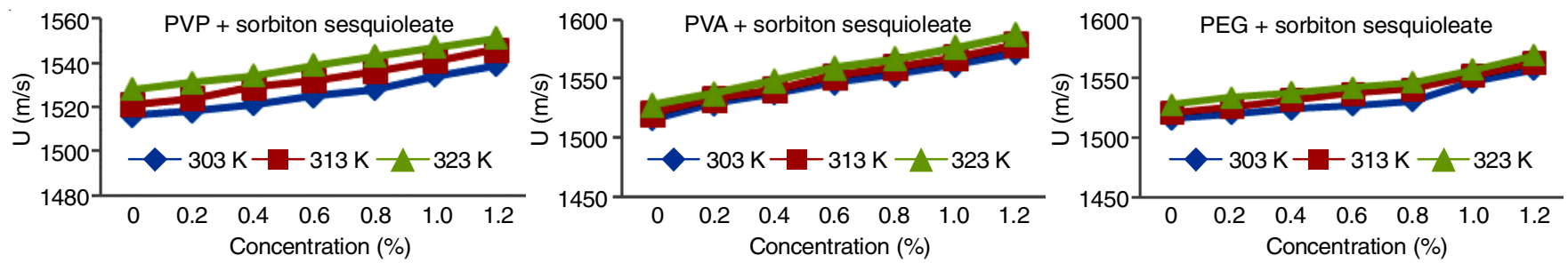

Fig. 1. Ultrasonic velocity $v$ s. concentration of aqueous solution of some polymers + sorbiton sesquioleate at different temperatures 


\begin{tabular}{|c|c|c|c|c|c|c|c|c|c|c|c|c|c|c|}
\hline & & & $\begin{array}{l}\text { ASON } \\
\text { QUIO }\end{array}$ & $\begin{array}{l}\text { E VEL } \\
\text { EATE }\end{array}$ & $\begin{array}{l}\text { ITY AI } \\
\text { SOME }\end{array}$ & $\begin{array}{l}\text { RELA } \\
\text { UEOL }\end{array}$ & $\begin{array}{l}\text { TABLE } \\
\text { iD ACO } \\
\text { POLYN }\end{array}$ & $\begin{array}{l}\text { TICA } \\
\text { eS A }\end{array}$ & $\begin{array}{l}\text { ARAM } \\
\text { FFERE }\end{array}$ & $\begin{array}{l}\text { ERS FO } \\
\text { T TEMPE }\end{array}$ & $\begin{array}{l}\text { SORE } \\
\text { RATUI }\end{array}$ & & & \\
\hline $\begin{array}{l}\underset{\underbrace{}}{\dot{\varepsilon}} \\
\stackrel{\dot{\Xi}}{0}\end{array}$ & $\begin{array}{l}\text { ô } \\
\dot{0} \\
\tilde{0}\end{array}$ & $\begin{array}{l}\text { Ton } \\
\Xi \\
\Xi \\
\square\end{array}$ & $\begin{array}{l}\widetilde{T} \\
\Xi \\
00 \\
\ddot{a} \\
a\end{array}$ & $\begin{array}{l}\hat{b} \tilde{T} \\
\times \underline{z} \\
x \tilde{z}\end{array}$ & 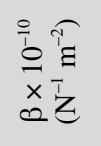 & 氚 & 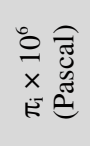 & $\simeq$ & 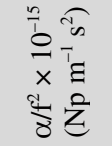 & 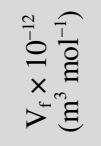 & 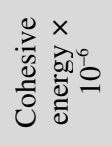 & $\begin{array}{l}n \\
\frac{n}{b} \\
0 \\
x \\
r\end{array}$ & 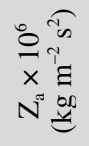 & $\omega^{5}$ \\
\hline & & & & & & Sorbitar & sesquiol & te $+\mathrm{PV}$ & & & & & & \\
\hline & $1: 1$ & 1521 & 1097 & 1.936 & 3.940 & 0.396 & 0.211 & 0.923 & 13.186 & 14.977 & 3.165 & 1.016 & 1.668 & 812 \\
\hline & $2: 1$ & 1525 & 1109 & 1.984 & 3.877 & 0.392 & 0.216 & 0.909 & 13.262 & 15.463 & 3.350 & 1.025 & 1.691 & 1246 \\
\hline 303 & $3: 1$ & 1528 & 1118 & 2.147 & 3.830 & 0.390 & 0.227 & 0.897 & 14.153 & 17.308 & 3.944 & 1.096 & 1.708 & 1365 \\
\hline & $4: 1$ & 1534 & 1126 & 2.372 & 3.774 & 0.386 & 0.241 & 0.886 & 15.343 & 20.044 & 4.847 & 1.193 & 1.727 & 1814 \\
\hline & $5: 1$ & 1531 & 1132 & 2.586 & 3.768 & 0.387 & 0.255 & 0.876 & 16.737 & 22.556 & 5.759 & 1.299 & 1.733 & 1846 \\
\hline & $1: 1$ & 1529 & 1092 & 1.845 & 3.917 & 0.394 & 0.211 & 0.929 & 12.427 & 14.044 & 2.975 & 0.963 & 1.669 & 1102 \\
\hline & $2: 1$ & 1532 & 1102 & 1.936 & 3.866 & 0.392 & 0.219 & 0.916 & 12.846 & 15.008 & 3.296 & 0.997 & 1.688 & 1337 \\
\hline 313 & $3: 1$ & 1536 & 1110 & 2.048 & 3.818 & 0.389 & 0.228 & 0.905 & 13.386 & 16.252 & 3.709 & 1.042 & 1.704 & 1450 \\
\hline & $4: 1$ & 1541 & 1121 & 2.291 & 3.756 & 0.386 & 0.244 & 0.892 & 14.683 & 19.157 & 4.678 & 1.147 & 1.727 & 1940 \\
\hline & $5: 1$ & 1536 & 1129 & 2.378 & 3.754 & 0.386 & 0.252 & 0.879 & 15.281 & 19.987 & 5.088 & 1.190 & 1.734 & 1947 \\
\hline & $1: 1$ & 1534 & 1088 & 1.658 & 3.905 & 0.394 & 0.206 & 0.933 & 11.099 & 12.022 & 2.482 & 0.863 & 1.668 & 1148 \\
\hline & $2: 1$ & 1539 & 1097 & 1.719 & 3.848 & 0.391 & 0.212 & 0.921 & 11.302 & 12.643 & 2.686 & 0.881 & 1.688 & 1438 \\
\hline 323 & $3: 1$ & 1543 & 1106 & 1.827 & 3.797 & 0.388 & 0.221 & 0.909 & 11.822 & 13.787 & 3.053 & 0.924 & 1.706 & 1557 \\
\hline & $4: 1$ & 1547 & 1114 & 1.975 & 3.750 & 0.386 & 0.232 & 0.898 & 12.590 & 15.423 & 3.587 & 0.987 & 1.723 & 1925 \\
\hline & $5: 1$ & 1541 & 1121 & 2.133 & 3.756 & 0.386 & 0.244 & 0.887 & 13.671 & 17.062 & 4.177 & 1.068 & 1.727 & 1868 \\
\hline & & & & & & Sorbitan & esquiol & te $+\mathrm{PV}$ & & & & & & \\
\hline & $1: 1$ & 1538 & 1119 & 2.132 & 3.777 & 0.387 & 0.223 & 0.909 & 13.7694 & 17.617 & 3.933 & 1.073 & 1.721 & 3110 \\
\hline & $2: 1$ & 1547 & 1131 & 2.347 & 3.694 & 0.383 & 0.236 & 0.896 & 14.7369 & 20.346 & 4.819 & 1.155 & 1.749 & 3165 \\
\hline 303 & $3: 1$ & 1554 & 1154 & 2.583 & 3.588 & 0.377 & 0.253 & 0.874 & 15.6817 & 23.442 & 5.931 & 1.235 & 1.793 & 3374 \\
\hline & $4: 1$ & 1550 & 1169 & 2.792 & 3.560 & 0.376 & 0.267 & 0.857 & 16.863 & 26.014 & 6.958 & 1.325 & 1.811 & 3577 \\
\hline & $5: 1$ & 1546 & 1178 & 2.842 & 3.551 & 0.376 & 0.273 & 0.845 & 17.1664 & 26.381 & 7.214 & 1.345 & 1.821 & 3627 \\
\hline & $1: 1$ & 1541 & 1112 & 1.942 & 3.786 & 0.388 & 0.219 & 0.915 & 12.5477 & 15.360 & 3.364 & 0.980 & 1.713 & 2886 \\
\hline & $2: 1$ & 1552 & 1121 & 2.161 & 3.703 & 0.383 & 0.233 & 0.905 & 13.5582 & 18.063 & 4.209 & 1.066 & 1.739 & 3000 \\
\hline 313 & $3: 1$ & 1560 & 1139 & 2.326 & 3.607 & 0.378 & 0.245 & 0.887 & 14.143 & 20.148 & 4.944 & 1.118 & 1.776 & 3160 \\
\hline & $4: 1$ & 1556 & 1148 & 2.573 & 3.597 & 0.378 & 0.261 & 0.874 & 15.6422 & 23.147 & 6.055 & 1.233 & 1.786 & 3221 \\
\hline & $5: 1$ & 1552 & 1159 & 2.724 & 3.582 & 0.377 & 0.273 & 0.860 & 16.5301 & 24.899 & 6.799 & 1.300 & 1.798 & 3328 \\
\hline & $1: 1$ & 1548 & 1096 & 1.789 & 3.807 & 0.389 & 0.214 & 0.930 & 11.5695 & 13.674 & 2.931 & 0.908 & 1.696 & 2562 \\
\hline & $2: 1$ & 1559 & 1115 & 1.938 & 3.690 & 0.383 & 0.226 & 0.911 & 12.0606 & 15.444 & 3.497 & 0.953 & 1.738 & 3106 \\
\hline 323 & $3: 1$ & 1567 & 1127 & 2.136 & 3.613 & 0.379 & 0.240 & 0.897 & 12.9509 & 17.850 & 4.292 & 1.028 & 1.766 & 3088 \\
\hline & $4: 1$ & 1561 & 1138 & 2.375 & 3.606 & 0.378 & 0.249 & 0.882 & 14.4258 & 20.627 & 5.145 & 1.141 & 1.776 & 3130 \\
\hline & $5: 1$ & 1557 & 1146 & 2.529 & 3.599 & 0.378 & 0.260 & 0.870 & 15.3719 & 22.382 & 5.835 & 1.213 & 1.784 & 3166 \\
\hline & & & & & & Sorbitar & esquiol & te + PEC & & & & & & \\
\hline & $1: 1$ & 1524 & 1092 & 1.968 & 3.942 & 0.396 & 0.212 & 0.927 & 13.386 & 15.376 & 3.266 & 1.034 & 1.664 & 865 \\
\hline & $2: 1$ & 1527 & 1096 & 2.046 & 3.913 & 0.394 & 0.218 & 0.919 & 13.785 & 16.209 & 3.539 & 1.067 & 1.673 & 947 \\
\hline 303 & $3: 1$ & 1531 & 1101 & 2.255 & 3.874 & 0.392 & 0.231 & 0.911 & 15.005 & 18.669 & 4.315 & 1.164 & 1.685 & 1060 \\
\hline & $4: 1$ & 1547 & 1107 & 2.296 & 3.774 & 0.387 & 0.234 & 0.904 & 14.729 & 19.318 & 4.528 & 1.155 & 1.712 & 1858 \\
\hline & $5: 1$ & 1541 & 1111 & 2.347 & 3.790 & 0.388 & 0.239 & 0.894 & 15.178 & 19.684 & 4.715 & 1.185 & 1.712 & 1722 \\
\hline & $1: 1$ & 1532 & 1087 & 1.845 & 3.919 & 0.395 & 0.211 & 0.933 & 12.411 & 14.068 & 2.971 & 0.964 & 1.665 & 1075 \\
\hline & $2: 1$ & 1537 & 1091 & 1.961 & 3.879 & 0.393 & 0.219 & 0.925 & 13.015 & 15.359 & 3.370 & 1.014 & 1.676 & 1205 \\
\hline 313 & $3: 1$ & 1541 & 1096 & 2.147 & 3.842 & 0.391 & 0.231 & 0.917 & 14.074 & 17.514 & 4.054 & 1.099 & 1.688 & 1263 \\
\hline & $4: 1$ & 1552 & 1102 & 2.215 & 3.767 & 0.387 & 0.236 & 0.909 & 14.136 & 18.394 & 4.354 & 1.112 & 1.710 & 1857 \\
\hline & $5: 1$ & 1546 & 1107 & 2.296 & 3.779 & 0.387 & 0.243 & 0.898 & 14.757 & 19.138 & 4.665 & 1.156 & 1.711 & 1750 \\
\hline & $1: 1$ & 1538 & 1081 & 1.642 & 3.910 & 0.394 & 0.204 & 0.939 & 10.977 & 11.880 & 2.429 & 0.855 & 1.662 & 1152 \\
\hline & $2: 1$ & 1542 & 1085 & 1.783 & 3.876 & 0.392 & 0.214 & 0.931 & 11.784 & 13.381 & 2.873 & 0.921 & 1.673 & 1211 \\
\hline 323 & $3: 1$ & 1546 & 1089 & 1.942 & 3.841 & 0.391 & 0.225 & 0.924 & 12.688 & 15.140 & 3.420 & 0.994 & 1.683 & 1239 \\
\hline & $4: 1$ & 1557 & 1094 & 2.107 & 3.770 & 0.387 & 0.236 & 0.916 & 13.415 & 17.148 & 4.059 & 1.059 & 1.703 & 1806 \\
\hline & $5: 1$ & 1553 & 1099 & 2.186 & 3.772 & 0.387 & 0.243 & 0.906 & 13.962 & 17.900 & 4.363 & 1.099 & & 1779 \\
\hline
\end{tabular}

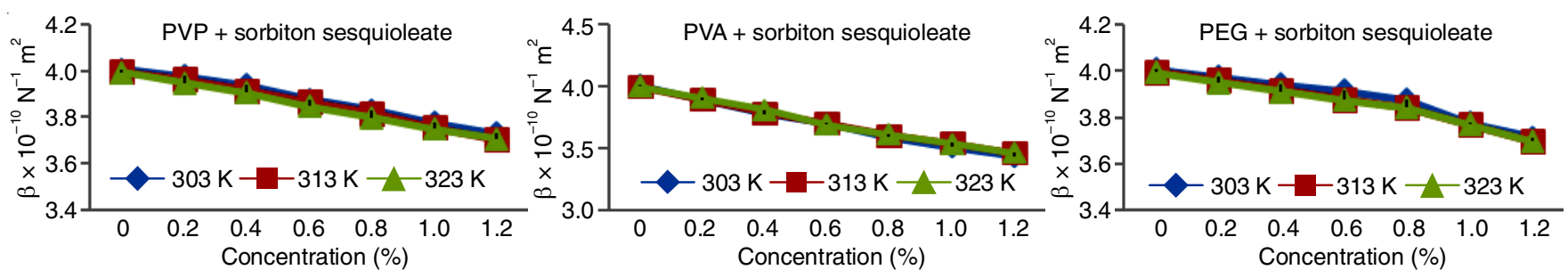

Fig. 2. Adiabatic compressibility vs. concentration of aqueous solution of some polymers + sorbiton sesquioleate at different temperatures 
static effects of polymers on the surrounding molecules [14]. The adiabatic compressibility falls with increase in temperature. The soap molecules in dilute solutions ionize in cations and anions, due to the decrease in adiabatic compressibility. These ions in solution are bordered by a coating of solvent molecules, firmly sure and oriented towards the ions. The orientation of solvent molecules round the ions is attributed to the effect of electrostatic field of ions, which disturbs the internal pressure and drops the compressibility of the solution. The inter molecular free length depends upon adiabatic compressibility and shows a behaviour similar to that of compressibility and inversely to that of ultrasonic velocity. On increasing the concentration the inter molecular free length decreases. This shows that there is a structural rearrangement in the binary mixture and suggests the presence of strong solute-solvent interactions [15]. If the temperature increases, density and compressibility decreases and ultrasonic velocity increases. It shows that the interactions between solute and solvent molecules are significant. Due to thermal expansion of liquids an increase in temperature reasons the free length to increase which is similar to adiabatic compressibility.

The increase of acoustic impedance values with solute concentration can be recognized to the effective solute-solvent interactions. It is also observed that acoustic impedance value for sorbitan sesquioleate + PVA is greater than that for other two systems. The non-linear variation of Rao's constant $\left(\mathrm{R}_{\mathrm{a}}\right)$ with concentration forecast the strong intermolecular link between the molecules of sorbitan sesquioleate with polymers. The positive values of solvation number indicate the structure forming tendency of the polymers [16]. A change in post micellization area exhibited by the values of solvation number, which may be credited to greater consumption of solvent molecules. This reduces the repulsive forces acting between polar heads of ionic micelles [9]. The increase of internal pressure with concentration and the positive values of solvation number confirm an increase in cohesive force, which again support the structure forming tendency of solutes.

If the concentration of sorbitan sesquioleate is increased the absorption coefficient value is also increased. This is due to the fact that the maximum reaction takes place at higher concentration [17]. The result shows that the transfer of energies more probable between two different molecules than with the molecules of the same species [18]. Free volume is the null space between the molecules because of rough packing of molecules. Fig. 3 shows the variation of free volume with concentration and temperature. The increase of free volume shows that the strength of interaction increases with solute concentration. It represents that there is strong interaction between the solute and solvent molecules [19]. If the concen- tration of sorbitan sesquioleate + polymer mixtures is increased, the cohesive energy also increased and this increment implies that the solute-solvent had a very strong bond in between them [20].

UV analysis: From the absorption study, the mixture of sorbitan sesquioleate + PVA has extremely good correlation $\mathrm{R}^{2}=0.986$, but poor correlation in mixture of sorbitan sesquioleate + PVP, $R^{2}=0.742$ and mixture of sorbitan sesquioleate + $\mathrm{PEG}, \mathrm{R}^{2}=0.957$. Aqueous mixture of sorbitan sesquioleate + PVA has high polarization power than the other two systems of sorbitan sesquioleate + PVP and sorbitan sesquioleate + PEG. In all the cases, polarization increases with increase in absorption as shown in Table-2.

\begin{tabular}{|c|c|c|}
\hline \multicolumn{3}{|c|}{$\begin{array}{c}\text { TABLE-2 } \\
\text { UV-VISIBLE ABSORBANCE VALUES OF SORBITAN } \\
\text { SESQUIOLEATE + PVP, SORBITAN SESQUIOLEATE + } \\
\text { PVA AND SORBITAN SESQUIOLEATE + PEG }\end{array}$} \\
\hline Sample name & $\begin{array}{l}\text { Concentration } \\
\left(\times 10^{-3}\right) \mathrm{mol} \mathrm{m}^{-3} \\
\end{array}$ & $\begin{array}{c}\text { Absorbance } \\
(\mathrm{Nm})\end{array}$ \\
\hline \multirow{4}{*}{$\begin{array}{c}\text { Sorbitan sesquioleate } \\
\text { + PVP }\end{array}$} & 0.0004 & 0.763 \\
\hline & 0.0006 & 0.851 \\
\hline & 0.0008 & 0.932 \\
\hline & 0.0010 & 1.745 \\
\hline \multirow{4}{*}{$\begin{array}{c}\text { Sorbitan sesquioleate } \\
+ \text { PVA }\end{array}$} & 0.0004 & 0.515 \\
\hline & 0.0006 & 0.742 \\
\hline & 0.0008 & 0.873 \\
\hline & 0.0010 & 1.032 \\
\hline \multirow{4}{*}{$\begin{array}{c}\text { Sorbitan sesquioleate } \\
+ \text { PEG }\end{array}$} & 0.0004 & 0.943 \\
\hline & 0.0006 & 0.987 \\
\hline & 0.0008 & 1.154 \\
\hline & 0.0010 & 1.285 \\
\hline
\end{tabular}

FTIR analysis: The Fourier transform infrared analysis was conducted to verify the possibility of interaction of chemical bonds between non-ionic surfactant with polymers. The FTIR spectra of pure non-ionic surfactant (sorbitan sesquioleate) and sorbitan sesquioleate blended in the ratio 1:1 with PVP, PVA or PEG were recorded in the transmittance mode in the range of 4000-400 $\mathrm{cm}^{-1}$ at a resolution of $1.0 \mathrm{~cm}^{-1}$.

The spectrum of sorbitan sesquioleate shows the characteristic absorption of band positions and intensities observed in FTIR spectrum. In sorbitan sesquioleate the peaks at 3536 and $3185 \mathrm{~cm}^{-1}$ were due to the presence of stretching $\mathrm{N}-\mathrm{H}$ group. The band at $2031 \mathrm{~cm}^{-1}$ indicates the presence of $\mathrm{C} \equiv \mathrm{C}$ group. The C-H stretching band was found in the range of $2915 \mathrm{~cm}^{-1}$. A band at $2915 \mathrm{~cm}^{-1}$ in sorbitan sesquioleate shifted to 2968 $\mathrm{cm}^{-1}$ in sorbitan sesquioleate + PVP, 2961 and $2943 \mathrm{~cm}^{-1}$ in sorbitan sesquioleate + PVA was found to lie in the region of stretching of methyl and propyl groups and in the case of sorbitan sesquioleate + PEG the C-H stretching band at 2863 $\mathrm{cm}^{-1}$ was found.
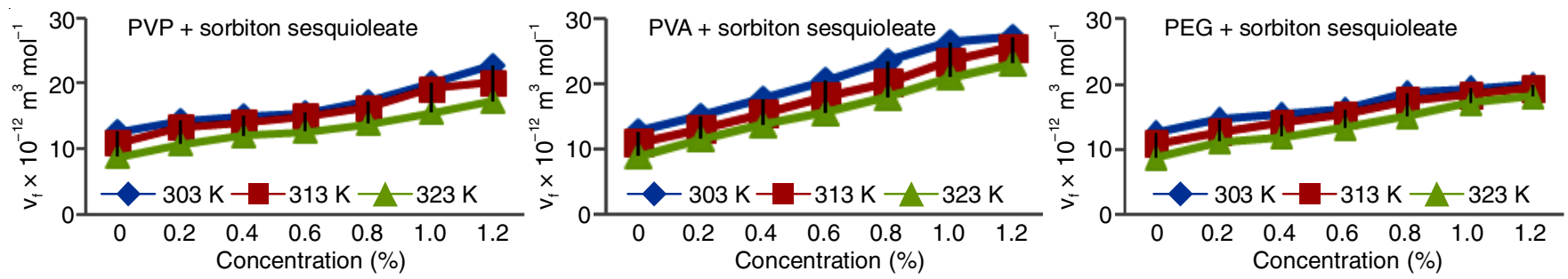

Fig. 3. Free volume $v$ s. concentration of aqueous solution of some polymers + sorbiton sesquioleate at different temperatures 
The intense peak at $1298 \mathrm{~cm}^{-1}$ in pure PVP shifted to 1278 $\mathrm{cm}^{-1}$ indicates the presence of C-O group in sorbitan sesquioleate + PVP. The peak at $2396 \mathrm{~cm}^{-1}$ in pure PVA moved to 2301 $\mathrm{cm}^{-1}$ indicates the presence of $\mathrm{C} \equiv \mathrm{C}$ band and 1372 to 1368 $\mathrm{cm}^{-1}, 1096$ to $1105 \mathrm{~cm}^{-1}$ shows the presence of C-O for sorbitan sesquioleate + PVA. In sorbitan sesquioleate $+\mathrm{PEG}, 1540 \mathrm{~cm}^{-1}$ lifted from $1698 \mathrm{~cm}^{-1}$ in pure PEG mention $\mathrm{C}=\mathrm{C}$ group. For sorbitan sesquioleate + PVP the band at $2843,873 \mathrm{~cm}^{-1}$, the peak at $958 \mathrm{~cm}^{-1}$ in sorbitan sesquioleate + PVA and 908, 841 $\mathrm{cm}^{-1}$ at sorbitan sesquioleate + PEG show newly created C-H stretching vibration bands. In sorbitan sesquioleate + PEG the new peak at $1105 \mathrm{~cm}^{-1}$ was assigned to $\mathrm{C}-\mathrm{O}$ band. However, sorbitan sesquioleate with PVA revealed a significant chemical interaction which is realized by observing all spectral bands of sorbitan sesquioleate + PVA loaded. Besides, FTIR studies showed that the sorbitan sesquioleate + PVA distribution was homogeneous.

\section{Conclusion}

The present study reveals that the intermolecular interaction of sorbitan sesquioleate with polymers (PVP, PVA and PEG) and the molecular association of sorbitan sesquioleate + PVA system is quite high compare to sorbitan sesquioleate + PVP and sorbitan sesquioleate + PEG systems. From UV analysis, the mixture of sorbitan sesquioleate + PVA has extremely good correlation $\mathrm{R}^{2}=0.986$ compared to other two mixtures. FTIR spectra, the result suggests that sorbitan sesquioleate + PVA blend has stronger intermolecular interaction than other blends. The present work clearly stated about that sorbitan sesquioleate + PVA has been used as a best additive and this composite had a lower foaming tendency due to lower surface tension and to make newer product.

\section{CONFLICT OF INTEREST}

The authors declare that there is no conflict of interests regarding the publication of this article.

\section{REFERENCES}

1. J.D. Pandy and Y. Akhtar, J. Pure Appl. Ultrason., 18, 108 (1996).

2. M.S. Aston, T.M. Herrington and T.F. Tadros, Colloids Surf., 62, 31 (1992);

https://doi.org/10.1016/0166-6622(92)80034-Y.

3. S. Jayakumar, N. Karunanidhi and V. Kannappan, J. Pure Appl. Ultrason., 20, 79 (1998).

4. H. Shirota and E.W. Castner, J. Chem. Phys., 125, 034904 (2006); https://doi.org/10.1063/1.2208356.

5. E.D. Goddard, J. Soc. Cosmet. Chem., 41, 23 (1990).

6. J.A. Faucher and E.D. Goddard, J. Colloid Interface Sci., 55, 313 (1976); https://doi.org/10.1016/0021-9797(76)90039-4.

7. E.D. Goddard and R.B. Hannan, J. Colloid Interface Sci., 55, 73 (1976); https://doi.org/10.1016/0021-9797(76)90010-2.

8. E.D. Goddard and R.B. Hannan, J. Am. Oil Chem. Soc., 54, 561 (1977); https://doi.org/10.1007/BF03027636.

9. D. Rodric and S.K. Upadhyaya, World J. Pharm. Pharm. Sci., 4, 1656 (2015).

10. A.M. Carrier and M.L. Standish, ed.: Z. Amjad, Polymer Mediated Crystal Habit Modification, In: Mineral Scale Formation and Inhibition. Springer, Boston, MA, Springer, pp. 63-71 (1995).

11. S. Kalyanasundaram, S. Sundaresan and J. Hemalatha, Bull. Electrochem., 15, 501 (1999).

12. E.D. Goddard, Colloids Surf., 19, 255 (1986); https://doi.org/10.1016/0166-6622(86)80340-7.

13. A.A. Patil, J. Chem. Pharm. Res., 5, 19 (2013).

14. L. Pena, E. Junquera and E. Aicart, J. Solution Chem., 24, 1075 (1995); https://doi.org/10.1007/BF00973523.

15. S. Ravichandran and C.R.T. Kumari, E-J. Chem., 8, 77 (2011); https://doi.org/10.1155/2011/741971.

16. V.M. Kagathara, M.R. Sanariya and P.H. Parsania, Eur. Polym. J., 36, 2371 (2000); https://doi.org/10.1016/S0014-3057(00)00006-9.

17. V.K. Syal, A. Chauhan and S. Chauhan, J. Pure Appl. Ultrason., 27, 61 (2005).

18. P.K. Sahoo, R. Mohapatra, A. Sahoo and S.K. Swain, J. Appl. Polym. Sci., 88, 3196 (2003); https://doi.org/10.1002/app.12158.

19. C. Shanmuga Priya, S. Nithya, G. Velraj and A.N. Kanappan, Int. J. Adv. Sci. Technol., 18, 59 (2010).

20. V. Karikalan, A. Panneerselvam and K. Vallalperuman, Dig. J. Nanomater. Biostruct., 13, 115 (2018). 